\title{
Embodied technological change, learning-by-doing and the productivity slowdown*
}

\author{
Raouf Boucekkine $^{\dagger} \quad$ Fernando del Río Omar Licandro $^{\ddagger}$
}

May, 2002

\begin{abstract}
The productivity slowdown faced by the US economy since the first oil shock has been associated with a rise in the decline rate of the relative price of equipment and a reduction in the rate of disembodied technical change. We build up a growth model in which learning-bydoing is the engine of both embodied and disembodied technological progress. A change in the relative efficiency of learning-by-doing from the consumption to the investment sector is shown to imply a technological reassignment consistent with the above mentioned evidence. This result derives from the interaction between the obsolescence costs inherent to embodiment and the learning-by-doing engine.

Keywords: Embodied technical progress, Obsolescence, Learningby-doing, Productivity slowdown.

Journal of Economic Literature: E22, E32, O40, C63.

${ }^{*}$ We would like to thank David de la Croix, Jean-François Fagnart, two anonymous referees and an associate editor for their most useful comments. Boucekkine acknowledges the financial support of the Belgian French speaking community (ARC 99/04-235) and of the Belgian Federal Government (PAI P5/10). del Río and Licandro acknowledge the financial support of the Spanish Ministry of Sciences and Technology (Grant SEC2000-

†IRES and CORE, Université catholique de Louvain. E-mail:

$\ddagger$ Universidad de Santiago de Compostela. E-mail: aedelrio@usc.es.

$\S$ European University Institute, Florence, and FEDEA. E-mail: omar.licandro@iue.it.
\end{abstract} 0260). boucekkine@ires.ucl.ac.be. 


\section{Introduction}

The most important technological advances are nowadays embodied in the new capital goods: In order for a firm to take advantage of the most up-todate information and communication technology devices, it is indispensable to acquire the most recent generations of computers and telecommunication tools compatible with these devices. The traditional neoclassical growth model is not aimed at capturing the implications of such a trend since it is based on the assumption that technological progress is disembodied, namely independent of capital accumulation. As documented in Greenwood and Yorukoglu (1997), two major stylized facts seriously undermine the neoclassical growth model: The steady decrease in the relative price of equipment investment and the secular rise in the equipment investment to GDP ratio. Both are incompatible with the long term properties of the neoclassical growth model. In contrast, these two facts can be rationalized in a canonical two-sector growth model assuming that part of technological advances are specific to the capital goods sector. Using this approach, Greenwood, Hercowitz and Krusell (1997) found that around 60\% of post-war US productivity growth can be attributed to embodied technological change.

The productivity slowdown faced by the US since the first oil shock has been recently associated with a rise in the decline rate of investment goods prices, as reported by Greenwood and Yorukoglu (1997), and a reduction in the rate of disembodied technological progress, as reported by Hornstein and Krusell (1996). These stylized facts are at the heart of the recent abundant literature on the reliability of the "New Economy" as a growth regime. The increasing role of the information and communication technologies in US growth is by now an unquestionable feature, even by the most outspoken "New Economy" 
skeptics. Since the technological advances conveyed by these technologies are embodied in nature, one may interpret this recent trend as a change in the composition of technological progress towards more embodiment. Is this good or bad for output growth? For Greenwood and Yorukoglu (1997), this should be good in the long run. In the short run however, the implementation of the new technologies at their full potential cannot be instantaneous, and requires a costly learning period during which productivity and growth may slowdown (see also David, 1990). For Gordon (1999), the invention of the electronic chip has nothing to do with the great inventions of the past (like electricity) in terms of spillovers from the innovative sectors to the rest of the economy. In his controversial article, Gordon claims that such spillovers do not yet show up in the data even during the boom period 1995:4-1999:1. In most of the recent contributions underlying the role of embodiment in the growth process (notable exceptions are in Krusell (1998) and Hsieh (2001)), technological progress and growth are exogenous. ${ }^{1}$ In this paper, technological progress relies on Arrowian learning-by-doing (LBD) in both the consumption and the investment goods sectors. The relative efficiency of the learning process in both sectors determines the relative importance of embodied and disembodied technical change. Hence, the growth rate is a function of the composition of technological progress. We conjecture that a technological reassignment, a change in the composition of technological progress, is at the roots of the US productivity slowdown. We model this technological reassignment by assuming that since the first oil shock the efficiency of learning in the capital goods sector has permanently increased at the expense of a permanent reduction of learning efficiency in the con-

\footnotetext{
${ }^{1}$ This is also the case in the literature of the 60 s dealing with the so-called embodied question, see Solow (1960) and Phelps (1962). A modern reincarnation of the debate around this question can be found in Hercowitz (1998).
} 
sumption goods sector. We show that such a shock generates a rise in the decline rate of investment prices and a reduction in the rate of disembodied technical change, consistently with the observations in Greenwood and Yorukoglu (1997) and Hornstein and Krusell (1996). Moreover, this technological reassignment generates a permanent productivity slowdown, i.e., a permanent reduction in per capita growth. In this framework, embodied technological progress is primarily characterized by obsolescence costs. These costs arise because under embodied technological progress the relative price of investment goes down permanently, increasing the user cost of capital. A technological reassignment towards more embodiment induces a permanent increase in the user cost of capital, which from the standard consumption smoothing argument tends to slowdown output growth.

As one can conclude from the paragraph just above, our findings crucially rely on the learning-by-doing growth engine. Obviously, Miracles, radical innovations are certainly needed to launch industrial revolutions, and thus R\&D activities are undeniably decisive. But as Greenwood and Yorukoglu (1997) claim, historically these eras are also "an age of continuous and gradual smaller innovations -an age of learning". Hence, though learning-by-doing is not the whole growth story, it is an important part of it, and so is the obsolescence mechanism we point out in this contribution.

The paper is organized as follows. Section 2 presents our two-sector LBD model. Section 3 gives our main findings. In particular the obsolescence costs mechanism is carefully described together with the role of technological reassignment in explaining the productivity slowdown. Section 4 concludes. 


\section{The model}

Our model relies on the two-sector economy proposed by Greenwood, Hercowitz and Krusell (1997). At equilibrium, it can be described by the following four equations under a Cobb-Douglas technology and assuming preferences with constant intertemporal elasticity of substitution:

$$
\begin{gathered}
y_{t}=z_{t} k_{t}^{1-\alpha}=c_{t}+i_{t}, \\
\dot{k}_{t}=q_{t} i_{t}-(\delta+n) k_{t}, \\
\frac{\dot{c}_{t}}{c_{t}}=\frac{1}{\sigma}\left((1-\alpha) z_{t} q_{t} k_{t}^{-\alpha}-\delta-\frac{\dot{q}_{t}}{q_{t}}-\rho\right), \\
\lim _{t \rightarrow \infty} \frac{k_{t}}{q_{t}} e^{-(\rho-n) t} c_{t}^{-\sigma}=0,
\end{gathered}
$$

where $y_{t}, k_{t}, c_{t}$ and $i_{t}$ are production, capital, consumption and gross investment at time $t$, respectively. All variables are in per-capita terms. (1) is the usual resource constraint with $0<\alpha<1$, the labor share. (2) gives the law of motion of efficient capital per-capita, with $0<\delta<1$ the depreciation rate, and $n>0$ the population growth rate. The third equation is the standard Euler equation yielded by growth models, with $\sigma>0$ and $\sigma \neq 1$ the inverse of the intertemporal elasticity of substitution, and $\rho>n>0$ the rate of time preference. Finally, equation (4) is the transversality condition.

The vector $\left(z_{t}, q_{t}\right)$ represents the state of technology at time $t$. An increase in $z_{t}$ rises the marginal productivity of all the capital stock, independently of its age structure. Hence, $z_{t}$ represents disembodied technological progress. In sharp contrast, $q_{t}$ only affects new equipment by equation (2), and represents embodied technological progress. There is a much more crucial difference between the two forms of technical change: Embodiment implies obsolescence,

and this is reflected in our model through the term $\frac{\dot{q}_{t}}{q_{t}}$ appearing in the 
Euler equation (3). Since technological progress is partly embodied, the user cost of capital includes the loss of value due to future technological improvements, which will only affect future capital goods. This feature is the major departure with respect to the standard optimal growth model. We now present the LBD extension of the model.

\section{Learning-by-doing in the two-sector economy}

Let us assume that endogenous technological progress is the result of LBD, as in Arrow (1962). We set $z_{t}=z k_{t}^{\gamma}$ and $q_{t}=q k_{t}^{\lambda}$, with $z, q, \gamma$ and $\lambda$ four strictly positive real numbers. Additionally we assume that: i) social returns to capital are constant, namely $\gamma+\lambda=\alpha$, and ii) the effects of capital accumulation on technical progress are not internalized by firms. As usual, condition i) is needed for a balanced growth path to exist, and condition ii) is consistent with the existence of a competitive equilibrium. As we will see later, assumption i) turns out to be crucial.

Under assumptions i) and ii), the system (1)-(4), describing the decentralized equilibrium of the considered economy, ${ }^{2}$ can be rewritten as a differential equation system on $k_{t}$ and $c_{t}, \forall t \geq 0$,

$$
\begin{gathered}
\dot{k}_{t}=(z q-\delta-n) k_{t}-q k_{t}^{\lambda} c_{t}, \\
\frac{\dot{c}_{t}}{c_{t}}=\frac{1}{\sigma}\left((1-\alpha) z q-\delta-\rho-\lambda \frac{\dot{k}_{t}}{k_{t}}\right), \\
\lim _{t \rightarrow \infty} \frac{k_{t}^{1-\lambda}}{q} e^{-(\rho-n) t} c_{t}^{-\sigma}=0,
\end{gathered}
$$

given the initial condition $k_{0}>0$. As it is standard in LBD models, the aggregate technology is linear, where $z q$ is equivalent to the $A$ term in an

\footnotetext{
${ }^{2}$ The central planner counterpart of the model is analyzed in Boucekkine, del Río and Licandro (1999).
} 
AK technology. Since individual firms do not internalize the LBD externality, the individual marginal productivity of capital is a fraction $(1-\alpha)$ of the aggregate marginal productivity $z q$.

Our model is closely related to two major references in the field, Frankel (1962) and Arrow (1962). In the former, the limit case $\lambda=0$ is analyzed, i.e., technological progress affects all the capital stock and it is totally disembodied. Under constant social returns to capital, namely if $\gamma=\alpha$, Frankel shows that a steady state growth path with an endogenous growth rate does arise. In Arrow (1962), the special case $\gamma=0$, technological progress only affects new capital goods and it is totally embodied. However, our formalization departs from Arrow's model in several respects. First, we do not consider Leontieff technologies as in the original Arrow's contribution. Secondly, the technological variables $q_{t}$ and $z_{t}$ are taken as functions of the cumulative efficient investment per capita while in Arrow, the efficiency of capital goods is measured by cumulative investment.

Note that $\gamma+\lambda$ is the total efficiency of the LBD process associated to our AK technology. In a context where the labor share $\alpha$ is constant, the condition $\gamma+\lambda=\alpha$ ultimately imposes that the total efficiency of the learning process must remain constant. In this sense, our model allows to analyze in a simple way the consequences of shifts in the composition of technological progress. A rise in $\lambda, \alpha$ being constant, increases the importance of embodied technological progress without changing the total learning efficiency of the economy. 


\section{Balanced growth and dynamics}

The steady state growth rate can be very easily computed from (5) and (6):

$$
g=\frac{1}{\hat{\sigma}}((1-\alpha) z q-\delta-\rho)
$$

where $\hat{\sigma}=\sigma+\frac{\lambda}{1-\lambda} \geq \sigma$, with the growth rate of capital being $g_{k}=\frac{g}{1-\lambda}>g$. The key difference with the standard results comes from the obsolescence term, $\frac{\lambda}{1-\lambda}$, which alters the corresponding term of the inverse of the intertemporal elasticity of substitution. We impose the following assumption:

Assumption $1(1-\alpha) z q>\delta+\rho>(1-\sigma) g+\delta+n$.

The first part of Assumption 1 implies $g>0$. The second part ensures that the transversality condition (7) holds and that equilibrium utility is bounded. It remains to see whether consumption is positive along a balanced growth path with the growth rate given by (8). Indeed, although Assumption 1 guarantees the positivity of consumption's growth rate, it does not ensure at first glance the positivity of consumption as computed from the resource constraint (5). We need a further condition:

Assumption $2 \frac{g}{1-\lambda}+\delta+n<z q$.

The following proposition establishes that Assumption 2 is a necessary and sufficient condition for the positivity of consumption.

Proposition 1 Under Assumption 1, a steady state equilibrium with a positive consumption to output share exists if and only if Assumption 2 holds.

The proof is in Appendix. It should be noted that Assumption 2 implies an upper bound for the long run growth rate of capital $g_{k}=\frac{g}{1-\lambda}<z q-$ $\delta-n$. Our interpretation of Assumption 2 follows : For a fixed $\lambda$, if $g_{k}$ is 
"too" high, the obsolescence cost as measured by $\frac{\dot{q}_{t}}{q_{t}}=\lambda g_{k}$, is so high that the rise in investment required to sustain this capital growth rate induces negative consumption. Indeed, we can prove a much stronger result under Assumptions 1 and 2: The previous steady state growth path is the unique solution path of the dynamic system (5)-(7). That is to say our model behaves like the standard AK model, in particular, it does not display any transitional dynamics. This property is established in the following proposition.

Proposition 2 Under Assumption 1 and Assumption 2, for any $k_{0}>0$, the dynamic system described by (5)-(7) yields a unique solution path, in which consumption per capita and the capital stock per capita grow at the constant rates $g$ and $g_{k}$, respectively.

The proof of Proposition 2 is in Appendix.

\section{Technological reassignment, obsolescence and the productivity slowdown}

The observed productivity slowdown faced by the US economy is contemporaneously associated with a rise in the decline rate of investment goods prices and a reduction in the rate of disembodied technological progress. We conjecture that such a technological reassignment is at the roots of the US productivity slowdown. In this section, we formalize our conjecture by hypothesizing an exogenous increase in the elasticity parameter $\lambda$, taking the labor share $\alpha$ constant, which is equivalent to assume a change in the composition of technological progress towards more embodiment.

Recall that the state of technology is represented by the vector $\left(z_{t}, q_{t}\right)$. We show hereafter that the postulated increase in the learning efficiency of the investment goods sector implies a technological reassignment, in the sense 
that the rate of embodied technical change increases at the cost of reducing the rate of disembodied technical change. By definition of the LBD process in the investment goods sector and using (8), the rate of embodied technical change can be written as

$$
\frac{\dot{q}_{t}}{q_{t}}=\frac{\lambda}{1-\lambda} g=\frac{(1-\alpha) z q-\delta-\rho}{\frac{1-\lambda}{\lambda} \sigma+1} .
$$

As expected, the rate of embodied technical change is an increasing function of $\lambda$. In our model, the decline rate of investment goods prices is by construction equal to the rate of embodied technical change. An increase in $\lambda$ implies an increase in the decline rate of investment goods prices, a prediction consistent with the evidence reported by Greenwood and Yorukoglu (1997). Since $z_{t}=z k_{t}^{\gamma}$, the rate of disembodied technical progress is $\frac{\dot{z}_{t}}{z_{t}}=\gamma g_{k}$. Using equation (8) together with $g_{k}=\frac{g}{1-\lambda}$ and the assumption of constant social returns to capital, we find:

$$
\frac{\dot{z}_{t}}{z_{t}}=\frac{\alpha-\lambda}{1-\lambda} g=\frac{\alpha-\lambda}{(1-\lambda) \sigma+\lambda}((1-\alpha) z q-\delta-\rho) .
$$

The rate of disembodied technical progress is a decreasing function of $\lambda$, a prediction consistent with the evidence reported by Hornstein and Krusell (1996).

Finally, the growth rate as measured in (8) is a decreasing function of $\lambda$. The previous results can be interpreted taking into account the obsolescence effect due to any shift in $\lambda$, and having in mind that in our exercise, an increase in $\lambda$ should be compensated by a reduction in $\gamma$ to hold the total learning efficiency constant. Due to the production function specification (1), a reduction in $\gamma$ has a direct and negative effect on the marginal productivity of capital. However, an increase in $\lambda$ improves the efficiency of new equipment due to the rise in the learning ability in the capital goods sector, and 
this tends to increase the marginal productivity of capital. Because social returns to capital are assumed to be constant, this positive effect completely compensates the negative effect of the reduction in $\gamma \cdot{ }^{3}$ However, the obsolescence effect does remain effective: An increase in $\lambda$ raises the obsolescence cost through the term $\frac{\dot{q}_{t}}{q_{t}}=\lambda g_{k}=\frac{\lambda}{1-\lambda} g$. From (6), it follows that an increase in the obsolescence cost lowers the equilibrium interest rate and so tends to reduce the growth rate of consumption, giving rise to the typical intertemporal substitution effect in optimal growth models. An increase in the fraction of embodied technological progress is bad for growth since it only affects the new capital goods, which in turn raises the velocity at which the old equipment becomes obsolete. In contrast, an increase in the weight of disembodied technological progress is good for growth since it affects all the capital goods, independently on their vintage.

It is therefore clear from equations (8), (9) and (10) that an increase in $\lambda$ can account for the productivity slowdown puzzle. If the post-1974 period implied a higher learning efficiency in the investment goods sector, captured here by an increase in $\lambda$, and a consequent reduction in the learning efficiency of the consumption goods sector, as captured by a reduction in $\gamma$, our model forecasts the productivity slowdown, the increase in the decline rate of investment goods prices and the reduction in the rate of disembodied technical change, as observed in the US data. Moreover, the productivity slowdown predicted by the model is a permanent phenomenon and not just the result of a very long adjustment process, as in Greenwood and Yorukoglu (1997) depending on learning effects and diffusion lags. This property is due to the LBD engine of growth: Technological reassignment induces a permanent rise

\footnotetext{
${ }^{3}$ A quick look at the Euler equation (6) is sufficient to conclude this. Indeed, the marginal productivity of capital at the decentralized equilibrium is given by $(1-\alpha) z q$. A shift in $\lambda$ has not effect on this expression.
} 
in the obsolescence costs associated to embodied technical progress, which add to the user cost of capital and lower the growth rate permanently.

Our story relies on LBD, and as claimed in the introduction, the role of LBD cannot be denied in the (long) periods following radical innovations. However, a complete treatment of the technological reassignment effect requires endogenizing $\lambda$ and $\gamma$ via R\&D activities, the composition of technological progress being ultimately endogenous. Our model can be seen as a first and -we think- useful approximation to this problem. The observed evolution of the R\&D to GDP ratio for the US economy does not show any important increase when we compare the sixties to the eighties and nineties (see the Data Brief of the National Science Foundation), which is consistent with our assumption of a constant learning efficiency for the whole economy. An endogenous growth model where embodied and disembodied R\&D activities were the engine of growth should be based on a reallocation of $R \& D$ expenditures, without any global increase.

\section{Conclusion}

We have developed a very simple endogenous growth model in which LBD is the engine of both embodied and disembodied technical progress, in line with Arrow (1962), Frankel (1962) and Romer (1986). In this endogenous growth set-up, we have shown that the nature of technological progress does matter in the determination of the long run growth rate. The key mechanism in our model is related to obsolescence costs, which are specific to embodied technological change.

More importantly, we suggest that if the post-1974 period implied a higher learning capacity in the sector of capital goods, and a smaller learning ef- 
ficiency in the consumption goods sector, our model accounts for the productivity slowdown as observed after the first oil shock. A higher learning elasticity in the capital goods sector implies a fall in the growth rate, an increase in the decline rate of the relative price of capital goods and a reduction in the rate of disembodied technical progress. In contrast to the usual learning explanation, as reported in Hornstein and Krusell (1996), and Greenwood and Yorukoglu (1997), ours relies on a technological reassignment effect and not on any loss of resources due to costly adoption.

The rise of information technologies means more embodied technological progress, and it is associated with a smaller productivity growth in the nondurable sector. A reassignment from disembodied to embodied technical change increases the velocity at which older capital goods become obsolete and the associated obsolescence cost, inducing a reduction of the growth rate. Hence while the optimism of the "New Economy" view is partially founded, given the huge productivity gains registered in the computers sector, the intrinsic characteristics of embodied technological progress call for more caution in the interpretation of the 1995-2000 boom period, and even more caution in any prospective study.

\section{References}

Arrow, K. (1962), The Economic Implications of Learning by Doing, Review of Economic Studies 29, 155-173.

Boucekkine, R., del Río, F. and Licandro, O. (1999), The Importance of the Embodied Question Revisited, Discussion Paper 9926, Université catholique de Louvain.

David, P.A. (1990), The dynamo and the Computer: An Historical Perspec- 
tive on the Modern Productivity Paradox, American Economic Review Papers and Proceedings 80, 355-361.

Frankel, M. (1962), The Production Function in Allocation and Growth: A Synthesis, American Economic Review 52, 995-1022.

Hsieh, C. (2001), Endogenous Growth and Obsolescence, Journal of Development Economics 66, 153-171.

Gordon, R. (1999), Has the "New Economy" Rendered the Productivity Slowdown Obsolete?, Manuscript, Northwestern University.

Greenwood, J., Hercowitz, Z. and Krusell, P. (1997), Long-Run Implications of Investment-Specific Technological Change, American Economic Review $87,342-362$.

Greenwood, J. and Yorukoglu, M. (1997), 1974, Carnegie-Rochester Conference Series on Public Policy 46, 49-95.

Hercowitz Z. (1998): The 'Embodiment' Controversy: A Review Essay, Journal of Monetary Economics 41, 217-224.

Hornstein, A. and Krusell, P. (1996), Can Technology Improvements Cause the Productivity Slowdown?, NBER Macroeconomics Annual, 209-275.

Krusell, P. (1998), Investment-Specific R \& D and the Decline in the Relative Price of Capital, Journal of Economic Growth 3, 131-141.

Phelps, E. (1962), The New View of Investment: A Neoclassical Analysis, Quarterly Journal of Economics 76, 548-567.

Romer, P. (1986), Increasing Returns and Long Run Growth, Journal of Political Economy 94, 1002-1037. 
Solow, R. (1960), Investment and Technological Progress, in K. Arrow, S.Karlin and P. Suppes (eds.), Mathematical Methods in the Social Sciences 1959, 89-104. Stanford University Press, Stanford.

\section{A Appendix}

Proof of Proposition 1: Let us define the consumption to output share as $\chi_{t}=\frac{c_{t}}{z k_{t}{ }^{1-\lambda}}$ and rewrite the resource constraint (5) as follows

$$
\frac{\dot{k}_{t}}{k_{t}}=z q-\delta-n-z q \chi_{t} .
$$

Since $\frac{\dot{c}_{t}}{c_{t}}=\frac{\dot{\chi}_{t}}{\chi_{t}}+(1-\lambda) \frac{\dot{k}_{t}}{k_{t}}$, the Euler equation (6) can be rewritten after some algebra as

$$
\frac{\dot{\chi}_{t}}{\chi_{t}}=\eta+\zeta \chi_{t}
$$

where

$$
\eta=\frac{(1-\alpha) z q-\delta-\rho}{\sigma}-\frac{(1-\lambda) \sigma+\lambda}{\sigma}(z q-\delta-n)
$$

and

$$
\zeta=\frac{(1-\lambda) \sigma+\lambda}{\sigma} z q
$$

The BGP solution is $\chi=-\frac{\eta}{\zeta}$. Since $\zeta$ is strictly positive, we need Assumption 2 to ensure the strict positivity of $\chi$.

Proof of Proposition 2: Denote by $\chi$ the (positive) steady state value of variable $\chi_{t}$, whose dynamics is described by equation (12). Observe that by (7) the transversality condition does not hold if

$$
\rho<(1-\lambda) \frac{\dot{k}_{t}}{k_{t}}-\sigma\left[\frac{\dot{\chi}_{t}}{\chi_{t}}+(1-\lambda) \frac{\dot{k}_{t}}{k_{t}}\right]+n
$$

when $t$ goes to infinity. We can prove now that $\chi_{t}=\chi$. We prove this by contradiction. If $\chi_{t}<\chi$ then $\frac{\dot{\chi} t}{\chi_{t}}$ goes to $\eta<0$ and $\chi_{t}$ goes to zero when 
$t \rightarrow \infty$. From (11) $\frac{\dot{k}_{t}}{k_{t}}$ goes to $z q-\delta-n$. Substituting $\frac{\dot{k}_{t}}{k_{t}}$ and $\frac{\dot{\chi} t}{\chi_{t}}$ by their limit values, it can be shown after some trivial algebra that the induced right hand side of (13) is higher than $\rho$. Thus, the transversality condition fails to hold, and this path cannot be an equilibrium.

If $\chi_{t}>\chi$, then $\frac{\dot{\chi}_{t}}{\chi_{t}}>0 \forall t \geq 0$ and $\chi_{t}$ goes to infinity. Thus, there exists a date $\bar{t}$ such that the resource constraint is violated (from (11) $\frac{\dot{k}_{t}}{k_{t}}$ goes to minus infinity, and then from (2) investment should become negative, which is excluded by assumption) and, therefore, this path can not be an equilibrium. Let us now show that, given $k_{0}>0, c_{t}$ and $k_{t}$ grow at constant rates for all $t \geq 0$. By definition of $\chi, c_{0}=\chi z k_{0}$. Moreover, from (11) the growth rate of $k_{t}$ is constant $\forall t \geq 0$, which implies, by constancy of $\chi$ that the grow rate of $c_{t}$ is also constant $\forall t \geq 0$. 